\title{
The role of mass media communication in public health: The impact of Islamic Republic of Iran broadcasting health channel on health literacy and health behaviors
}

\author{
Mohammad Hossein Saei ${ }^{1}$, Sardar Valadi ${ }^{2}$, Kianoosh Karimi $^{3}$, Mohammad Khammarnia ${ }^{4 *}$ (D) \\ Received: 14 Jun 2020 \\ Published: 26 Apr 2021
}

Abstract

Background: By informing and educating, the Media play a main role in increasing the health literacy of the community. Broadcasting health channels (BHCs) are established to improve health literacy and public health worldwide. This study was aimed to evaluate the role of Islamic Republic of Iran the broadcasting health channel (IRIB HC) on public health.

Methods: A cross-sectional, comparative study was performed on 500 participants throughout 6 urban areas in Tehran, the capital of Iran in 2019. About 250 of the samples were included in viewing the health channel group. A standard questionnaire was used to measure the levels of public health in the 2 groups. Data were analyzed and compared using SPSS software version 25.

Results: According to the results, health literacy was higher in the group that used the health channel rather than the other group. Also, with regard to physical and psychological health levels, a significant difference was observed between audiences and nonaudiences $(\mathrm{p}=0.013, \mathrm{p}=0.001$, respectively).

Conclusion: The IRIB HC has positive effects on increasing the level of health literacy, Physical and psychological health, and consequently improving public health. Therefore, these channels have a great role in the implementation of health polices to improve health status.

Keywords: Mass Media, Public Health, Health Literacy, Iran

Conflicts of Interest: None declared

Funding: None

*This work has been published under CC BY-NC-SA 1.0 license.

Copyright $($ Iran University of Medical Sciences

Cite this article as: Saei MH, Valadi S, Karimi K, Khammarnia M. The role of mass media communication in public health: The impact of Islamic Republic of Iran broadcasting health channel on health literacy and health behaviors. Med J Islam Repub Iran. 2021 (26 Apr);35:54. https://doi.org/10.47176/mjiri.35.54

\section{Introduction}

Public health is recognized as a public priority in all societies and is one of the most important indicators for measuring the dimension of sustainable development in all nations (1). In addition, in the last decades and following the 1986 Ottawa International Conference, the importance of empowering the community to actively participate in improving their healt $\mathrm{h}$ has been emphasized more than ever $(2,3)$. Health education as a central and integral part of health services has a great role in increasing healthy

Corresponding author: Dr Mohammad Khammarnia, khammarnia@zaums.ac.ir

1. News and Journalism Department, Media and Communication Faculty, IRIB University, Tehran, Iran

2. Department of Research in Social Communication, Communication and Media Faculty, IRIB University, Tehran, Iran

3. Media Management Department, Faculty of Management, University of Tehran, Tehran, Iran

4. Health Promotion Research Center, Zahedan University of Medical Sciences, Zahedan, Iran behaviors by raising knowledge about public health and promoting health related activities (4-6).

The mass media, especially radio and television, as one of the main pillars of education $(7,8)$ and information $(9$, $10)$ in the society can take a good role in promoting public health. Nabi et al (11) noted that the media has a great power in influencing individual and public health. Also, the media shapes an important knowledge resource about health literacy (HL) at the individual and public levels.

$\uparrow$ What is "already known" in this topic:

Health education, as a central and integral part of health services, has a great role in increasing healthy behaviors. The mass media, especially radio and television, can take a good role in promoting public health.

$\rightarrow$ What this article adds:

Health Channels have positive effects on increasing the level of health literacy. Health channels could also improve physical and psychological health. 
HL is a term introduced in the 1970s (12) that has become an increasingly important concept in public health (13). It is related to the capacities of the community to meet the various demands of health in a modern society (14). HL is an individual's capacity of achievement, interpretation, and comprehension of primary health care (PHC) information and care required for appropriate decision-making (15). It involves a collection of skills, such as listening, reading, analysis, decision-making, and power of applying these abilities in health-related conditions. It does not essentially relate to one's level of education or general literacy $(16,17)$. The World Health Organization (WHO) introduced HL as an important determiner of health services. Also, HL has been suggested internationally to create an association with continuously monitoring and coordinating strategic activities, particularly with the aim of promoting health services (18). While it is not yet clear how HL affects health-related consequences, there is a myriad of evidence that more of the unwanted health outcome are due to inadequate HL (19). The WHO has mentioned HL as a key mechanism to meet the healthrelated sustainable development goals (SDGs) (20). Also, according to the U.S. health care strategy center reports, those with low HL have fewer chances of comprehending health staff's oral or written assistance. Therefore, they experience a lower health state and pay more for physicians' visits (21). They are less lucky in performing selfcare performances as well as protective acts and pay more medical expenditure (22). Therefore, all members of the community need to deepen their understanding of how the health and well-being of individuals, families, communities, and societies are dependent on a complex array of social, environmental, and political forces (23). One way to increase HL is the use of media. Mass media are intensively used in public health. Vast sums are paid annually for supplies and salaries that have gone into the creation and distribution of booklets, pamphlets, television programs, et cetera (24). The media not only spread knowledge, but also inform people over a period of time. This ultimately helps in the change of attitude, knowledge, and practice (KAP) of the audience for achieving better health (25). These media are used at all levels of public health in the hope that the following will be achieved: the learning of accurate health information, the changing of health attitudes and standards, and the creation of new health performance (26). The mass media obviously can be an actual tool for health promotion, whether the attempt is on a national or local scale; it can dismiss the negative thoughts about health issues in the minds of people and create awareness about health dimensions (27). As Daniel Catalán noted, "we should stop arguing whether they are more or less effective than other strategies or whether one channel is better than another. Instead, we should carefully formulate our conceptual model of how we expect an intervention to work and then evaluate it accordingly." (25)

The Islamic Republic of Iran Broadcasting Health Channels (IRIB HC) called 'Salamat Tv" has been lunched since 2008 to help other institutions in the society to increase HL in the community. The policy of IRIB HC is to support the national development in the field of public health by increasing public literacy, developing the right attitude, responsibility, empowerment, optimal performance, and active participation of individuals, families, and the community. Therefore, this study aimed to evaluate the performance of the IRIB HC in increasing the audience's health knowledge and HL among community.

\section{Methods}

A cross-sectional, comparative study was performed in Tehran, the capital of Iran, in 2019. We tried to determine average hours that audiences are watching IRIB HC programs. In this regard, the citizens of Tehran as the study population were examined.

\section{Sample Size Determination}

The statistical population of this study was all individuals of the 6 urban areas of the Tehran. According to official statistics, the region's population was about 1000 000. Therefore, we used the following formula; about 250 people were determined as the study sample in each group.

$$
n=\frac{\left(Z_{1-\alpha / 2}+Z_{1-\beta}\right)^{2}\left(S_{1}^{2}+S_{2}^{2}\right)}{\left(\mu_{1}-\mu_{2}\right)^{2}}=250
$$

Then, 1 cluster was selected from each of the 6 urban areas, and within the clusters, individuals were selected by available sampling and entered into the 2 groups, with one group including 250 audiences of IRIB Heath Channel and the other 250 who did not see the IRIB Health channel.

Study tools: A standard 45-item questionnaire was used in a five-choice Likert scale. The questionnaire used in this study included demographic variables, evaluation of health literacy, physical health levels, and data on the psychological health levels.

Validity and Reliability of the Questionnaire: To assess the reliability of the research questionnaire, the instrument was distributed among 60 participants and subsequently analyzed by Cornbrash's Alpha formula. As a result, the overall internal reliability (Cronbach's alpha $=0.827$ ) was determined, indicating the appropriate reliability of the questionnaire (28). Also, the Kolmogorov-Smirnov test was used to ensure data normality. The results of the test indicated that the data were normally distributed $(\mathrm{p}<0.05)$.

\section{Research Implementation}

At first, to design the questionnaire, we used the WHO report on the European HL survey nd was published in 2013 (12, 29). The HLS-Q12 short version of the European Health Literacy, reflecting a conceptual model of 4 cognitive domains across 3 health domains, was used. To validate and localize the questionnaire, we referred it to 5 experts from the Health Policy Council of IRIB for further review. After finalizing the questionnaire, it was distributed to the entire target sample based on multistage cluster sampling.

At the beginning of data gathering phase, the objectives 
of the study were explained to the participants and they were assured that information would remain confidential. Moreover, the researchers explained that the participants' contribution to the study is completely voluntary. Then, an informed consent form was signed by the participants.

After data collection, the data were analyzed using descriptive and analytical statistics, such as independent samples $t$ test, by SPSS software v 21 .

This research has been reviewed and approved by the Islamic Republic of Iran Broadcasting University.

\section{Results}

According to Table 1, most of the respondents were female and about $58(23 \%)$ of them had a bachelor's degree or higher. Other demographic variables are shown in Table 1 .

Also, we tried to determine average hours that audiences are watching IRIB HC programs. The results demonstrated that, on average, audiences watched 2.64 hours of
IRIB HC programs per day. Furthermore, more than 75\% of the participants were satisfied with IRIB HC programs (Table 2).

The comparison of health literacy levels in the 2 groups are shown in Table 3. The analysis of the data through the questionnaire revealed that the health literacy level of IRIB CH audience was higher than the nonaudiences (Table $3)$.

To compare health literacy level between the 2 groups, we used independent samples $t$ test. According to the results and with regard to physical health level, a significant difference $(\mathrm{p}<0.001)$ was detected between audiences and nonaudiences. Also, psychological health level among the 2 groups had a significant difference $(\mathrm{p}=0.013)$ (Table 4$)$.

\section{Discussion}

This study aimed to evaluate the performance of the IRIB HC in increasing the audience health knowledge and HL among the community. The results showed that health

Table 1. Frequency of Demographic Variables of the Participants in 2019

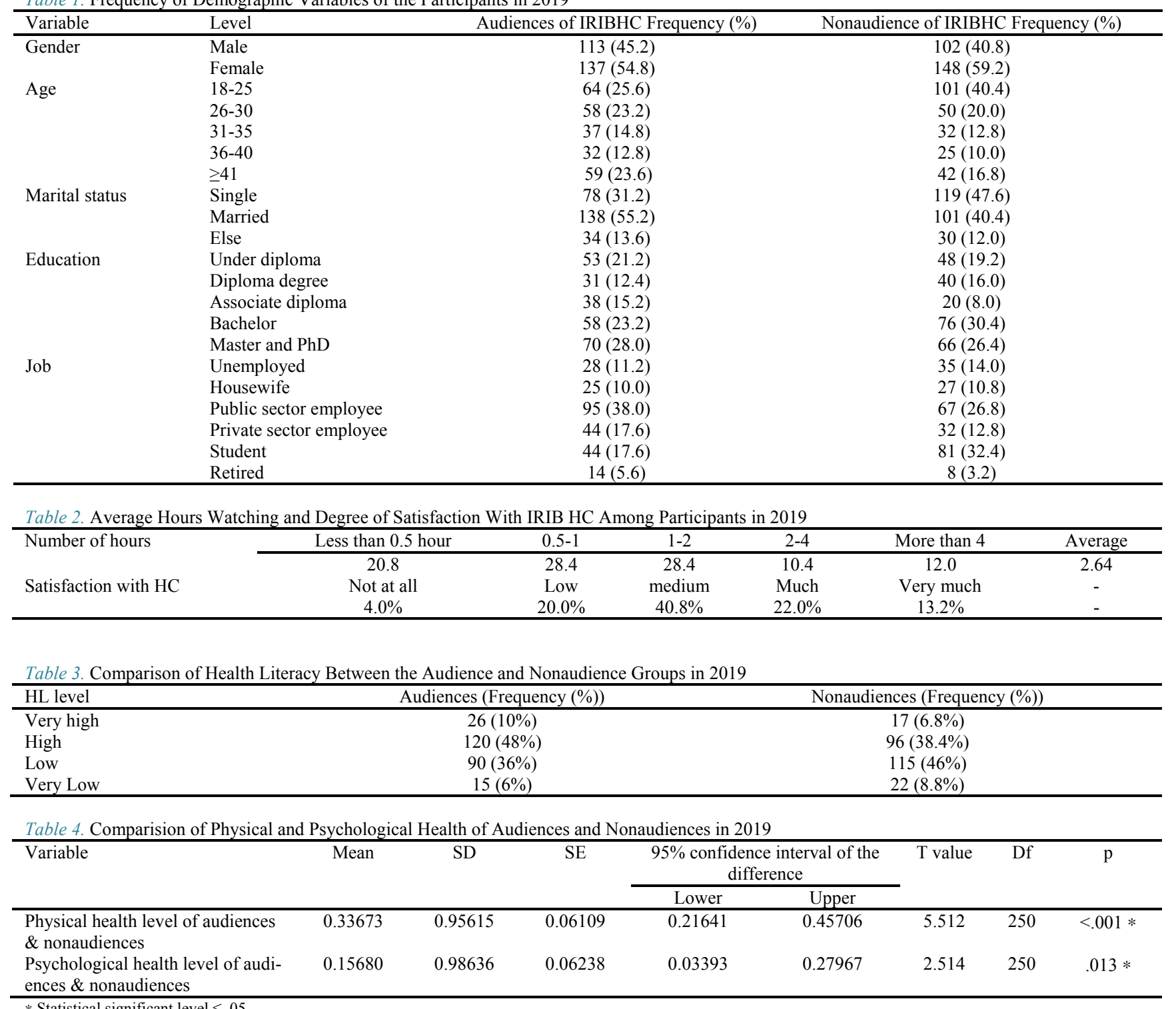


channel is still the mainstream media for people and could promote HL among audiences. Therefore, it can be found that IRIB HC programs have been able to enhance the HL of people. Television by its important role in entertainment, education, information, and also by indicting reliable information sources, has succeed in making itself a reference media in any family. It is notable that the invention of television, as a public service and an entry to the people's homes before invention of interactive media based on the internet platforms, has had a great impact on the current position of television in homes. In this regard, a study in Uganda showed that the mass media promote client knowledge and is a perceived available support mechanism in facing challenges (30), Also, Nabi et al (11) noted the media has great power in influencing individual and public health. Also, the media shapes important knowledge resources about HL at the individual and public levels. Moreover, Allen (31) demonstrated the role of $\mathrm{HC}$ and health advertising on increasing knowledge, information seeking, and other health behaviors. Therefore, those who view HC, compared with those who do not view it, have the ability to better understand their health status, have better knowledge levels about health issues, and learn about the ways to prevent and treat common diseases.

According to the results, television is a common medium for most of the people. In this regard, McConnell declared that the world health television channel had an impressive effect on health status, so these channels allow access to critical health information in developing countries (32). It should be noted that the improper use of television has several side effects, such as obesity and low physical activity. In this regard, Sharma found that reducing television time time may be an effective strategy for improving health and academic performance in adolescents (33).

The results demonstrate that people who are audiences of IRIB HC programs in terms of physical and psychological health, behave better than those who are not audiences of such programs. According to Fung results, TV watching can influence mental processes, and subsequently the newly adopted attitude can influence behavior (34). Therefore, with regard to physical and psychological health level, IRIB HC has a successful role in improving public health.

\section{Limitations of the study}

This was a cross-sectional study conducted on a limited population, so generalizing its results to larger populations should be done with more caution. An empirical study is recommended to make a better decision in this regard.

\section{Conclusion}

The result of this survey showed that IRIB HC programs have positive effects on HL level, and consequently improve public health in a community. Therefore, the IRIB HC has a great role in the implementation of health policy to improve the level of public health. It is recommended that programs of health channels be planned by taking into account common and emerging diseases.
Conflict of Interests

The authors declare that they have no competing interests.

\section{References}

1. Strezov V, Evans A, Evans TJ. Assessment of the Economic, Social and Environmental Dimensions of the Indicators for Sustainable Development. J Sustain Dev. 2017;25(3):242-253,

2. Mcqueen DV, De Salazar L. Health promotion, the Ottawa Charter and 'developing personal skills': a compact history of 25 years. Health Prom Int. 2011;26(suppl-2):194-201.

3. Eriksson M, Lindström B. A salutogenic interpretation of the Ottawa Charter. Health Promot Int. 2008;23(2):190-199.

4. Yoshida I, Kobayashi T, Sapkota S, Akkhavong A. Evaluating educational media using traditional folk songs ('lam') in Laos: a health message combined with oral tradition. Health Promot Int. 2012;27(1):52-62.

5. Cecilia A, Davia MA. Education is a key determinant of health in Europe: a comparative analysis of 11 countries. Health Promot Int 2011;26(2):163-170.

6. Shojaeifar M, Niknami Sh, Mirbalochzahi A, Khammarnia M, Alireza Khorram A. Comparison of the effect of educational methods on students' knowledge, attitude and behavior about hookah smoking. Electron Physician. 2017 Feb 25;9(2):3870-3877

7. Liu S, Liangliang C, Zhao X. The role of mass media in education policies: a Chinese case study. J High Educ Policy Manag. 2019;41(2):186-203,.

8. Rao C JM, Kumar P. The role of mass media in education and paucity decline. Int J Physic Soc Sci. 2017;7(2):9-23.

9. Mazumder BH. Role of mass media and the indian democracy. Int J Media Cult Politics. 2019:258.

10. Saikia R. Role of mass media in creating environmental awareness. Natl J Multidiscip Res Dev. 2017;1(2):1-4.

11. Nabi RL, Oliver MB. Media Processes and effects. SAGE Publications, 2009.

12. Kristine S, Broucke SV, Fullam J, Doyle G, Pelikan J, Slonska Z, et al. Health literacy and public health: A systematic review and integration of definitions and models. BMC Public Health. 2012:12.

13. Osborne RO, Batterham RW, Elsworth GR, Hawkins M, Buchbinder $\mathrm{R}$. The grounded psychometric development and initial validation of the Health Literacy Questionnaire (HLQ). BMC Public Health. 2013;13(658).

14. Hashemi-Shahri SM, Khammarnia M, Ansari-Moghaddam A, Setoodehzadeh F, Okati-Aliabad H, Peyvand M. Sources of news as a necessity for improving community health literacy about COVID-19. Med J Islam Repub Iran. 2020;34(1):453-455.

15. Khammarnia M, Setoodezadeh F, Ansari-Moghadam A, Yusefi A, Eskandari M, Alinejad Ranjbar A, et al. Relationship between health literacy of cancer patients and shared clinical decision-making in a Middle East country. Epidemiol Biostat Public Health. 2018;15(1).

16. Nam S, Chesla C, Stotts NA, Kroon L, Janso SL. Barriers to diabetes management: patient and provider factors. Diabetes Res Clin Pract. 2011;93(1):1-9.

17. Safari Moradabadi A, Aghamolaei T, Ramezankhani A, Dadipoor S. The Health Literacy of Pregnant Women in Bandar Abbas. J School Public Health Institue Public Health Res. 2017;15(9):121-132.

18. Reisi M, Javadzade SH, Mostafavi F, Sharifirad G, Radjati F, Hasanzade A. Relationship between health literacy, health status, and healthy behaviors among older adults in Isfahan, Iran. J Educ Health Promot. 2012;1:31.

19. Dadipoor S, Ramezankhani A, Aghamolaei T, Rakhshani F, SafariMoradabadi A. Evaluation of Health Literacy in the Iranian Population. Health Scope. 2018;7(3):e62212.

20. World Health Organization. Regional Office for Europe. (2013). Health literacy: the solid facts. World Health Organization. Regional Office for Europe.

21. Budhathoki SS, Pokharel PK, Suvajee G, Limbu S, Bhattachan M, Osborne RH. The potential of health literacy to address the health related UN sustainable development goal 3 (SDG3) in Nepal: a rapid review. BMC Health Serv Res. 2017;1(17):237.

22. Scott TL, Gazmararian JA, Williams MV, Baker DW. Health literacy and preventive health care use among Medicare enrollees in a managed care organization. Med Care. 2002;40(5):395-404.

23. Howard DH, Sentell T, Gazmararian JA. Impact of health literacy on 
socioeconomic and racial differences in health in an elderly population. J Gen Intern Med. 2006;21(8):857-861.

24. Freedman DA, Bess KD, Tucker HA, Boyed DL, TuchmanAM, Wallston KA. Public Health Literacy Defined. Am J Prev Med. 2009:446-451.

25. Catalán-Matamoros D. The Role of Mass Media Communication in Public Health. Health Manag Diff ApprSolut. 2011:399-414.

26. Sharma MSK, Gupta YK. Mass Media for Health Education (A Study in the State of Rajasthan). GRAM i J. 2017;1(1):26-39.

27. Wakefield MA, Loken B, Hornik RC. Use of mass media campaigns to change health behavior. Lancet. 2010 Oct 9;376(9748):1261-1271.

28. Cronbach LJ. Coefficient alpha and the internal structure of tests. Psychometrika. 1951;16(3):297-334.

29. World health organization, Constitution of the world health organization, WHO, 2006. https://www.who.int/governance/eb/ who constitution en.pdf

30. Franco G, Ndibaisa J, Slivia1 N. Women Mobile Lifeline Channel Is a Key Stimulant of MCH Services Use in Resource Constrained Settings: A Success Story of Women Health Channel Uganda. Iproceedings. 2019;5(1):e15239

31. Allen GC, McBride CM, Haardörfer R, Roberts MC. Associations between Objective Television Exposure and Cancer Perceptions in a National Sample of Adults. Cancer Control. 2019 Jan-Dec;26(1).

32. McConnell H, Haile-Mariam T, Rangarajan S. The World Health Channel: an innovation for health and development. World Hosp Health Serv. 2004.

33. Sharma B, Chavez RC, AJeong AS, Nam EW. Television Viewing and Its Association with Sedentary Behaviors, Self-Rated Health and Academic Performance among Secondary School Students in Peru. Int. J. Environ. Res. Public Health 2017;14(4):383.

34. Fung AYH, Lau AHY. The Role of the Mass Media in Health Care. Prim Care Revisit. 2020:67-79. 